\title{
Intra-aortic balloon counterpulsation reduces mortality in large anterior myocardial infarction complicated by persistent ischaemia: a CRISP-AMI substudy
}

\author{
Citation for published version (APA): \\ van Nunen, L. X., van 't Veer, M., Schampaert, S., Rutten, M. C. M., van de Vosse, F. N., Patel, M. R., \& Pijls, N. \\ H. J. (2015). Intra-aortic balloon counterpulsation reduces mortality in large anterior myocardial infarction \\ complicated by persistent ischaemia: a CRISP-AMI substudy. Eurolntervention, 11(3), 286-292. \\ https://doi.org/10.4244/EIJY14M09_10
}

\section{Document license: \\ TAVERNE}

DOI:

10.4244/EIJY14M09_10

Document status and date:

Published: 01/07/2015

\section{Document Version:}

Publisher's PDF, also known as Version of Record (includes final page, issue and volume numbers)

\section{Please check the document version of this publication:}

- A submitted manuscript is the version of the article upon submission and before peer-review. There can be important differences between the submitted version and the official published version of record. People interested in the research are advised to contact the author for the final version of the publication, or visit the $\mathrm{DOI}$ to the publisher's website.

- The final author version and the galley proof are versions of the publication after peer review.

- The final published version features the final layout of the paper including the volume, issue and page numbers.

Link to publication

\footnotetext{
General rights

- You may freely distribute the URL identifying the publication in the public portal. follow below link for the End User Agreement:

www.tue.nl/taverne

\section{Take down policy}

If you believe that this document breaches copyright please contact us at:

openaccess@tue.nl

providing details and we will investigate your claim.
}

Copyright and moral rights for the publications made accessible in the public portal are retained by the authors and/or other copyright owners and it is a condition of accessing publications that users recognise and abide by the legal requirements associated with these rights.

- Users may download and print one copy of any publication from the public portal for the purpose of private study or research.

- You may not further distribute the material or use it for any profit-making activity or commercial gain

If the publication is distributed under the terms of Article $25 f a$ of the Dutch Copyright Act, indicated by the "Taverne" license above, please 


\section{Intra-aortic balloon counterpulsation reduces mortality in large anterior myocardial infarction complicated by persistent ischaemia: a CRISP- AMI substudy}

Eurolntervention 2015;11:286-292 published online ahead of print September 2014. DOI:

10.4244/EIJY14M09_10

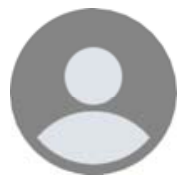

Lokien X. van Nunen1,2, MD; Marcel van 't Veer1,2, PhD; Stéphanie Schampaert1,2, MSc; Marcel C.M. Rutten2, PhD; Frans N. van de Vosse2, PhD; Manesh R. Patel3, MD; Nico H.J.

Pijls1,2*, MD, PhD

7. Department of Cardiology, Catharina Hospital Eindhoven, Eindhoven, The Netherlands; 2. Department of Biomedical Engineering, Eindhoven University of Technology, Eindhoven, The Netherlands; 3. Division of Cardiology, Department of Medicine, Duke Clinica

\section{Abstract}

Aims: This substudy investigated IABP support in large STEMI complicated by persistent ischaemia within the original CRISP-AMI trial.

Methods and results: Patients were included if the ECG at admission showed summed ST deviation ( $\Sigma S T-D) \geq 15 \mathrm{~mm}$ and the ECG post PCl showed poor ST resolution (<50\%). Endpoints evaluated were all-cause mortality at six months and the composite endpoint of death, cardiogenic shock or new or worsening heart failure at six months. One hundred and fortynine patients had $\Sigma$ ST-D $\geq 15 \mathrm{~mm}$ (mean $\Sigma S T-D 24 \pm 8 \mathrm{~mm}$ ). Of these patients, 36 (24\%) showed poor ST resolution (15 patients in the IABP group; 21 patients in the control group). Mean age was $55 \pm 11$ years, $89 \%$ were male. Mean systolic and diastolic blood pressures were $135 \pm 31$ $\mathrm{mmHg}$ and $83 \pm 22 \mathrm{mmHg}$, respectively. The left anterior descending coronary artery was the infarct-related artery in all cases, primary PCl was successful in 94\%. At six months, zero patients in the IABP group died versus five patients in the control group (0\% versus 24\%; $\mathrm{p}=0.046$ ). There was a trend towards statistical significance in the composite endpoint (one patient [7\%] versus seven patients [33\%]; $p=0.06)$.
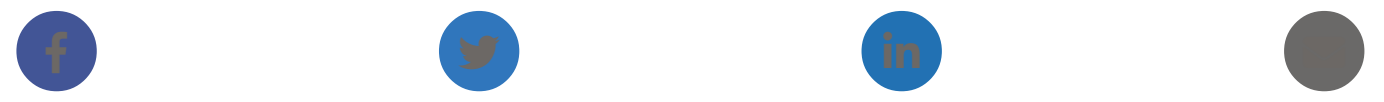
Conclusions: In this substudy, use of IABP was associated with decreased six-month

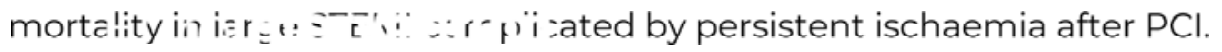

\section{Introduction}

Intra-aortic balloon pump (IABP) counterpulsation has been used as a haemodynamic support system for more than four decadesl. The IABP inflates and deflates in synchrony with the cardiac cycle, thereby augmenting diastolic aortic pressure and reducing afterload, resulting in increased coronary blood flow and decreased myocardial workload and oxygen demand2,3. The Counterpulsation Reduces Infarct Size Pre-PCI for AMI (CRISP-AMI) trial hypothesised that IABP as adjunct to revascularisation reduced final infarct size in patients with anterior wall STEMI without shock ${ }^{4}$. It was a multicentre randomised trial, including 337 patients who were randomised to receive either IABP before primary $\mathrm{PCl}$, or $\mathrm{PCl}$ alone. The primary endpoint, final infarct size as assessed by cardiac MRI, showed no difference between the two groups and a trend towards larger infarctions in the IABP group ( $42.1 \%$ versus $37.5 \%, p=0.06$ ). All-cause mortality at six months occurred less frequently in the IABP group, although it was not statistically significant ( $2 \%$ versus $5 \%, \mathrm{p}=0.12$ ). The exploratory composite endpoint of death, shock, or new or worsening heart failure did reach statistical significance in favour of the IABP group ( $5 \%$ versus $12 \%, p=0.03)$.

Interpretation of the ECG plays a fundamental role in the assessment of patients presenting with acute myocardial infarction. Not only the extent of ST elevation, but also the presence of ST resolution provides important prognostic information5,6. Early regression of ST deviation is associated with lower risk of death, recurrent ischaemia, reinfarction and congestive heart failure, while poor ST resolution, impaired myocardial blush grade, or impaired TIMI flow after primary PCl (i.e., markers of persistent ischaemia) are associated with a poor prognosis7-9. Earlier studies showed a possible beneficial effect of IABP support in acute myocardial infarction complicated by persistent ischaemia10,11.

In this sub-analysis of the CRISP-AMI trial, we evaluated the effect of IABP on outcome in patients with electrocardiographic signs of large anterior myocardial infarction complicated by persistent ischaemia despite primary $\mathrm{PCl}$, i.e., patients with the worst prognosis.

\section{Methods}

The methods used in the original CRISP-AMI trial have been described extensively12. In short, a total of 337 patients were randomised to be treated by primary $\mathrm{PCl}$ with or without adjunctive IABP support. If randomised to IABP, the device was implanted prior to the PCI procedure. In the present substudy, we focused on the patients with electrocardiographic signs of large myocardial infarction on the ECG at admission and with signs of persistent ischaemia, i.e., poor ST resolution at ECG post $\mathrm{PCl}$ (as described below).

\section{ELECTROCARDIOGRAPHIC ANALYSIS}

After manually identifying the J point to the nearest $0.5 \mathrm{~mm}$, ST deviation was measured 40 $\mathrm{ms}$ after the J point to the nearest $0.1 \mathrm{mV}$. The summed ST deviation ( $\Sigma S T-D)$ was calculated by adding the sum of ST elevation in the anterior leads (leads V1 to V6, I and aVL) to the sum of ST depression measured in reciprocal leads (leads II, III and aVF), if applicable. ST resolution (ST-R) was definod as the percent reduction in $\Sigma$ ST-D on the ECG nost PCl. 
All standard 12-lead ECGs were evaluated by an independent experienced cardiologist, blinded

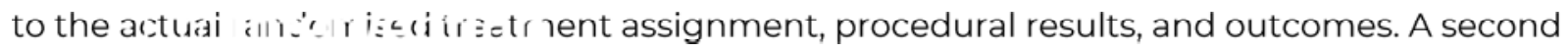
independent and experienced cardiologist, who was also blinded to randomisation as well as results, randomly reassessed 10\% of the study ECGs as second reader. Agreement by repeated measurement was 95\%.

For this substudy, we included those patients with a $\Sigma S T-D \geq 15 \mathrm{~mm}$ at admission. We excluded patients with left bundle branch block at baseline, paced ventricular rhythm, and patients with $\Sigma$ ST-D $<15 \mathrm{~mm}$. Patients were categorised based on the degree of ST-R: good ST-R (defined as $\geq 50 \%$ ) and poor ST-R (defined as $<50 \%$ ). The latter group was the target population in this subanalysis (Figure 1).

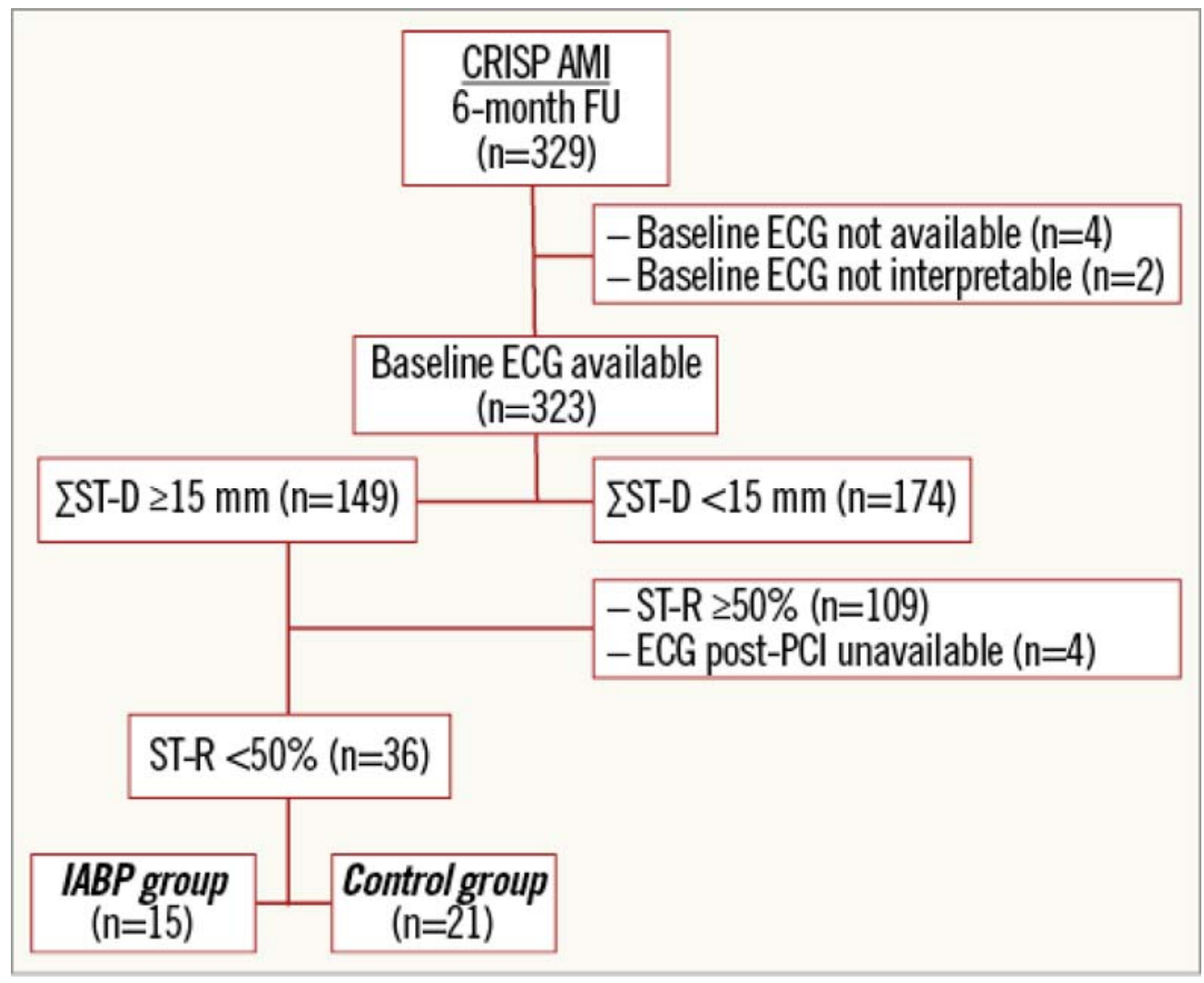

Figure 1. Flow chart of the substudy population. Flow chart of selection of patients in this substudy of the CRISPAMI trial. ECG: electrocardiogram; FU: follow-up; ¿ST-D: summed ST deviation; ST-R: ST resolution

\section{OUTCOME MEASURES}

The primary endpoint of the original CRISP-AMI trial was infarct size as a percentage of the total left ventricular mass as measured by cardiac MRI. Primary safety endpoints included allcause mortality and the rate of major adverse cardiac events including death, repeat myocardial infarction and heart failure at discharge, at 30 days, and at six months.

The present substudy was not pre-specified and not powered for the chosen endpoints.

Our primary clinical endpoints were all-cause mortality at six months, and the composite endpoint of death, cardiogenic shock and new or worsening heart failure at six months. Safety endpointsincluded major bleedina events according to the Global Use of Strategies To Open Corona teries (GUSTO) trial13. effects of IABP on in size as a percentage eft 
ventricular mass and left ventricular ejection fraction were not outcome measures in this

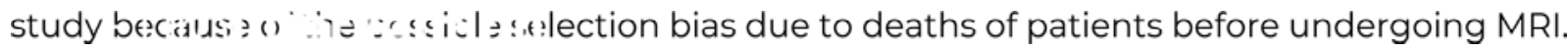

\section{STATISTICAL ANALYSIS}

Patient characteristics are reported as percentages for discrete variables, while continuous variables are presented as mean \pm standard deviations. Discrete variables were compared using the $\mathrm{X}^{2}$ or Fisher's exact test as appropriate. Continuous variables were compared using the Student's t-test or Mann-Whitney $U$ test as appropriate.

In correspondence with the original CRISP-AMI trial, Kaplan-Meier analyses and log-rank tests were used to compare time to primary endpoint, and time to composite endpoint of death, cardiogenic shock and new or worsening heart failure. The acquired data were analysed using IBM Statistical Package for Social Sciences (SPSS) for Windows Version 19.0.0.1 (IBM Corporation, Armonk, NY, USA). All statistical tests were two-tailed and a p-value $<0.05$ was considered statistically significant.

\section{Results}

In the CRISP-AMI trial, a total of 329 patients were included in the six-month follow-up (Figure 1). Baseline ECGs were available in 323 patients (98\%). In this population, 149 patients were classified as having large anterior wall myocardial infarction with $\Sigma$ ST-D $\geq 15 \mathrm{~mm}$ on the ECG at admission. In these patients, 109 patients were categorised as having good ST-R (more than $50 \%$ ) and 36 patients as having poor ST-R (less than 50\%). In four patients, the ECG post PCI was unavailable. Of those 36 patients with large myocardial infarction and poor ST-R, reflecting persistent ischaemia, 15 patients had been randomised to undergo primary $\mathrm{PCI}$ with IABP support, while 21 patients underwent primary $\mathrm{PCl}$ alone.

\section{BASELINE AND PROCEDURAL CHARACTERISTICS}

The baseline characteristics of the study cohort of patients with large myocardial infarction and poor ST-R $(n=36)$ are presented in Table 1. Mean age was $55 \pm 11$ years and $89 \%$ were male. At presentation, the mean $\Sigma$ ST-D was $24 \pm 8 \mathrm{~mm}$, which was well balanced between the two groups (treated with and without IABP as adjunct to PCI). Systolic blood pressure was $135 \pm 31$ $\mathrm{mmHg}$ on average, while diastolic blood pressure was $83 \pm 22 \mathrm{mmHg}$. Heart rate at presentation was $84 \pm 16$ beats per minute.

In accordance with the original population of the CRISP-AMI trial, patients were treated in a fast manner with a mean time from first hospital contact to first device used on the infarctrelated artery (IRA) of $97 \pm 39$ minutes in the IABP group versus $71 \pm 25$ minutes in the control group ( $p=0.04$ ) (Table 1). This difference was the time used for implanting IABP. There was no difference in the mean time from symptom onset to first hospital contact $(129 \pm 79$ minutes in the IABP group versus $150 \pm 82$ minutes in the control group, $\mathrm{p}=0.46$ ). There were no other statistically significant differences in baseline characteristics between the IABP group and the control group, except the previously mentioned time from first hospital contact to first device used on the IRA.
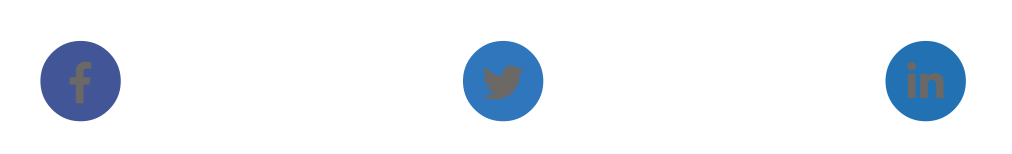


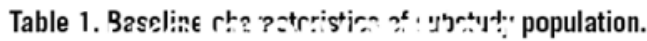

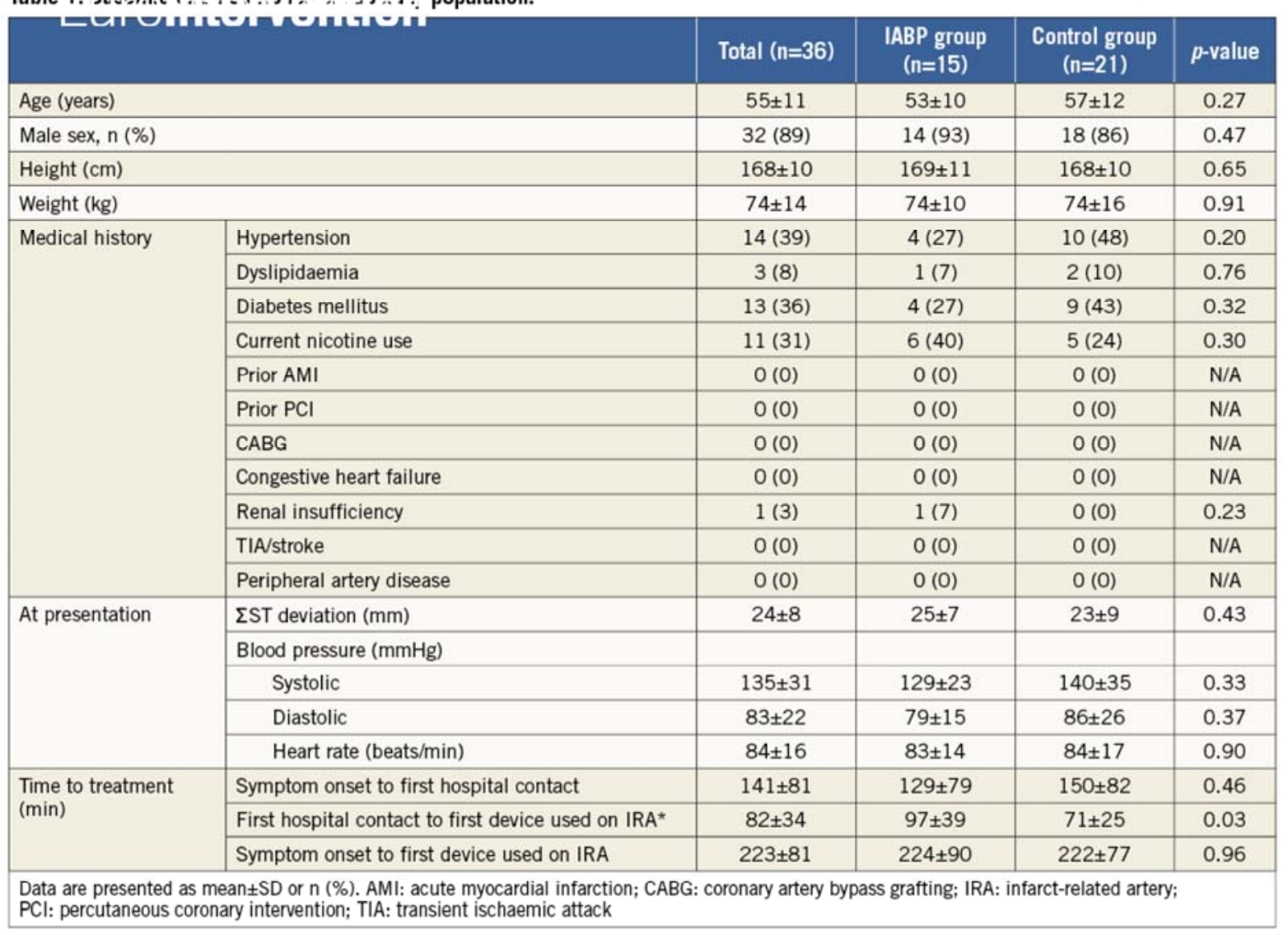

The left anterior descending coronary artery (LAD) was the IRA in all cases, and PCI was performed in $94 \%$ of all cases (Table 2). In $81 \%$ of the cases, the LAD was totally occluded at the initial angiogram. Primary PCI was successful in 34 patients (94\%; post-intervention TIMI flow grade 3). One patient underwent revascularisation with coronary artery bypass grafting instead of $\mathrm{PCl}$. 


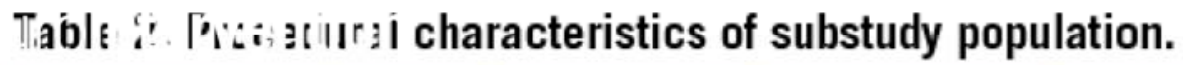

\begin{tabular}{|c|c|c|c|c|}
\hline \multirow{2}{*}{\multicolumn{2}{|c|}{ Infarct-related artery }} & Total $(n=36)$ & $\begin{array}{l}\text { IABP group } \\
\quad(n=15)\end{array}$ & $\begin{array}{c}\text { Control } \\
\text { group }(n=21)\end{array}$ \\
\hline & & & & \\
\hline \multicolumn{2}{|c|}{ Left anterior descending } & $36(100)$ & $15(100)$ & $21(100)$ \\
\hline \multicolumn{5}{|c|}{ IRA stenosis location* } \\
\hline \multicolumn{2}{|l|}{ Proximal } & $23(64)$ & $9(60)$ & $14(67)$ \\
\hline \multicolumn{2}{|l|}{ Mid } & $14(39)$ & $6(40)$ & $8(38)$ \\
\hline \multicolumn{5}{|l|}{ PCI } \\
\hline \multicolumn{2}{|l|}{ Performed } & $34(94)$ & $14(93)$ & $20(95)$ \\
\hline \multicolumn{2}{|c|}{ Not performed because of: } & $2(6)$ & $1(7)$ & $1(5)$ \\
\hline \multicolumn{2}{|l|}{ CABG } & $1(3)$ & $0(0)$ & $1(5)$ \\
\hline \multicolumn{2}{|c|}{ Technical limitations } & $1(3)$ & $1(7)$ & $0(0)$ \\
\hline \multicolumn{5}{|c|}{ Infarct-related artery TIMI flow } \\
\hline \multirow{4}{*}{$\begin{array}{l}\text { Pre-intervention } \\
\text { grade }\end{array}$} & 0 & $29(81)$ & $12(80)$ & $17(81)$ \\
\hline & 1 & $4(11)$ & $2(13)$ & $2(10)$ \\
\hline & 2 & $2(6)$ & $1(7)$ & $1(5)$ \\
\hline & 3 & $1(3)$ & $0(0)$ & $1(5)$ \\
\hline \multirow{4}{*}{$\begin{array}{l}\text { Post-intervention } \\
\text { grade }^{\star *}\end{array}$} & 0 & $1(3)$ & $1(7)$ & $0(0)$ \\
\hline & 1 & $0(0)$ & $0(0)$ & $0(0)$ \\
\hline & 2 & $0(0)$ & $0(0)$ & $0(0)$ \\
\hline & 3 & $34(94)$ & $14(93)$ & $20(95)$ \\
\hline \multicolumn{5}{|c|}{ Non-IRA interventions } \\
\hline \multicolumn{2}{|l|}{ Left main } & $1(3)$ & $1(7)$ & $0(0)$ \\
\hline \multicolumn{2}{|l|}{ Right coronary } & $1(3)$ & $1(7)$ & $0(0)$ \\
\hline \multicolumn{5}{|c|}{$\begin{array}{l}\text { Data are presented as } n(\%) \text {. * In some cases multiple lesions were treated in one } \\
\text { procedure. ** } 0 \text { ne patient was treated by CABG instead, which is why there is no } \\
\text { post-intervention TIMI grade available. CABG: coronary artery bypass grafting; } \\
\text { IRA: infarct-related artery; PCl: percutaneous coronary intervention }\end{array}$} \\
\hline
\end{tabular}

In the IABP group ( $n=15)$, patients were supported by IABP for $22 \pm 9$ hours. At discharge, patient? treated with aspiri $\% ; n=31$ ), clopidogrel 0 ; $n=25$ ) or prasugrel 
beta-blocker (82\%; n=27), statin therapy (94\%; n=31), and either an angiotensin-converting enzynie in'ribi (1 r c' 'siciers:; receptor blocker (58\%; n=19). There were no differences in medical treatment at discharge between the IABP group and the control group.

There were no bleeding complications in the IABP group. Major bleeding requiring transfusion occurred in one patient in the control group.

\section{OUTCOME}

In Figure 2, divided into three panels, are shown the Kaplan-Meier survival curves at six months of the original CRISP-AMI trial population (panel $A ; N=329 ; p=0.12$ ), the population with electrocardiographic signs of large anterior wall myocardial infarction (panel $B ; n=149 ; p=0.10$ ), and the population of the present substudy (panel $C ; n=36 ; p=0.046$ ), respectively. The survival curves diverge most in the subgroup of patients with the worst prognosis. In the population of patients with signs of large anterior wall myocardial infarction complicated by persistent ischaemia, zero patients in the IABP group died versus five patients in the control group at sixmonth follow-up ( $0 \%$ versus $24 \%$; log-rank $p=0.046$; panel C). Four patients died before hospital discharge due to refractory cardiogenic shock $(n=1)$ or unsuccessful resuscitation and/or defibrillation $(n=3)$.

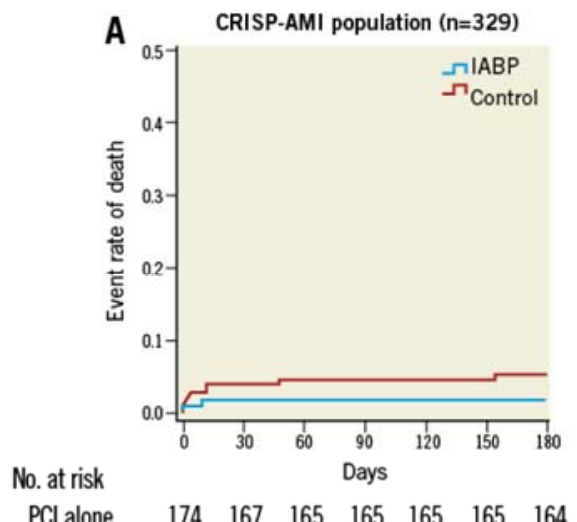

$\begin{array}{llllllll}\mathrm{PCl} \text { alone } & 174 & 167 & 165 & 165 & 165 & 165 & 164\end{array}$ IABP plus PCl $157 \quad 154 \quad 154 \quad 153 \quad 153 \quad 153 \quad 153$
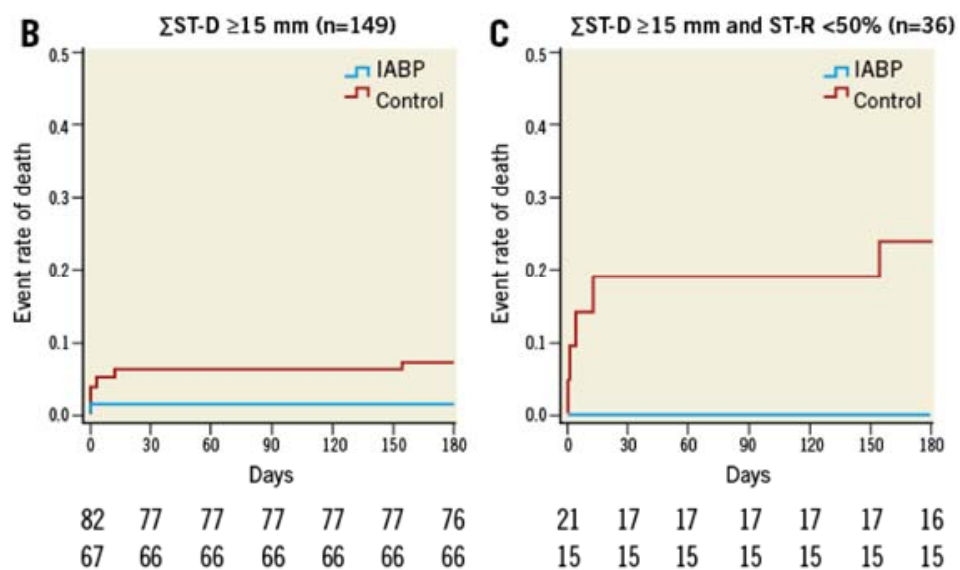

Figure 2. All-cause mortality rate at six months in the different (sub)populations. All-cause mortality rate over six months in all patients receiving IABP plus PCI (blue line) or PCl alone (red line) in the total CRISP-AMI population (three patients vs. nine patients; log-rank $\mathrm{p}=0.12$; panel A); in patients with large myocardial infarction (one patient vs. six patients; log-rank p=0.10; panel B); and in patients with large myocardial infarction and persistent ischaemia (zero patients vs. five patients; log-rank $\mathrm{p}=0.046$; panel C).

Table 3 shows the survival estimates in different subpopulations within the original CRISP-AMI trial, i.e., small myocardial infarction, large myocardial infarction and large myocardial infarction complicated with persistent ischaemia, respectively. In the IABP group, survival estimates remain constant in the different populations, while in the control group there is a clear decrease in survival in large infarctions, especially when accompanied by persistent ischaemia.
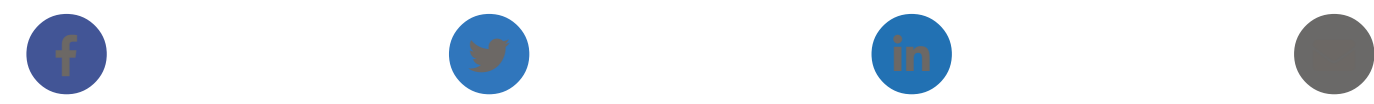


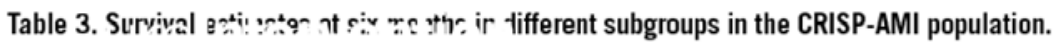

\begin{tabular}{|c|c|c|c|c|c|c|}
\hline-0 & \multicolumn{2}{|c|}{ Small MI ( $\Sigma S T-D<15$ mm; $n=180$ ) } & \multicolumn{2}{|c|}{ Large MI ( $\Sigma S T-D \geq 15$ mm; $n=149$ ) } & \multicolumn{2}{|c|}{$\begin{array}{l}\text { Large } \mathrm{Ml} \text { and poor ST-R ( } \Sigma \mathrm{ST}-\mathrm{D} \\
\geq 15 \mathrm{~mm} \text { and ST-R }<50 \% ; \mathrm{n}=36 \text { ) }\end{array}$} \\
\hline & $\%(n)$ & $95 \% \mathrm{Cl}$ & $\%(n)$ & $95 \% \mathrm{Cl}$ & $\%(n)$ & $95 \% \mathrm{Cl}$ \\
\hline IABP group & $97.8(87)$ & $95-100$ & $98.5(66)$ & $96-100$ & $100(15)$ & N/A \\
\hline Control group & $96.7(88)$ & $93-100$ & $92.7(76)$ & $87-98$ & $76.2(16)$ & $56-96$ \\
\hline
\end{tabular}

Data are presented as \% (n) and 95\% confidence intervals. Note: $95 \%$ confidence intervals of survival in the IABP group in the subgroup of patients with large myocardial infarction complicated by poor ST resolution are not described since there was no event. Cl: confidence interval; MI: myocardial infarction; ST-D: ST deviation; ST-R: ST resolution

The composite endpoint of death, cardiogenic shock and new or worsening heart failure at six months was reached by one patient in the IABP group and seven patients in the control group and was not statistically significant, although a strong trend was present $(7 \%$ versus $33 \%$, logrank $\mathrm{p}=0.06)$.

In the control group (21 patients), in five patients (24\%) crossover to IABP therapy occurred. Reasons for crossover in these five patients were progression of haemodynamic deterioration in all five patients. There was no crossover from the IABP group to the control group.

An MRI was successfully performed in 28 patients (13 patients in the IABP group [87\%], 15 patients in the control group [71\%]). Four patients died prior to the MRI procedure (all from the control group) and four patients were unable to tolerate the MRI procedure. The mean infarct size was $43 \pm 19 \%$ of left ventricular mass ( $48 \pm 24 \%$ versus $39 \pm 12 \%, p=0.26)$. Mean left ventricular ejection fraction on MRI was $41 \pm 10 \%$, and not statistically different between the two groups $(38 \pm 12 \%$ versus $44 \pm 8 \%, p=0.13)$. There was a trend towards less microvascular obstruction in the control group (11.8 $\pm 8.6 \%$ versus $5.4 \pm 7.0 \%, p=0.052)$. Indirect measures of infarct size, like peak enzymes (CK, CK-MB, and troponin) were available in less than $30 \%$ of the study population and therefore not analysed.

Finally, in the population of patients with large myocardial infarction ( $\Sigma S T-D \geq 15 \mathrm{~mm} ; \mathrm{n}=149$ ), the presence of poor ST resolution was associated with an increased rate of death (OR 17.419; 95\% Cl: 2.0-154.7; $p=0.01$ ).

\section{Discussion}

In this non-pre-specified substudy of the CRISP-AMI trial, intra-aortic balloon pump counterpulsation reduced mortality at six months in patients with large anterior myocardial infarction and persistent ischaemia. The significance was achieved despite the rather small substudy population. There were no complications associated with the use of IABP.

To the best of our knowledge, there are no randomised trials comparing survival in patients with large myocardial infarction and persistent ischaemia treated with IABP. However, the survival rates in this kind of patient treated medically are well described and are comparable to the survival of the control group in this substudy9,14,15. Rezkalla et al previously described a 30-day mortality of $12 \%$ in patients with severely impaired myocardial blush grade after PCI for acute myocardial infarction9. In a pre-specified substudy of the APEX-AMI trial, a randomised double-blind placebo-controlled trial on the use of intravenous pexelizumab before primary $\mathrm{PCl}$, the relationship between early ST-segment recovery and outcome was evaluated15. Patients with inadequate ST resolution, analysed with several different methodologies, were at higher $r$ f death, heart failure hock up to 90 days af STEMI. The HORIZON MI ECG 
substudy showed that absent ST resolution 60 minutes post $\mathrm{PCl}$ occurred in almost $20 \%$ of the

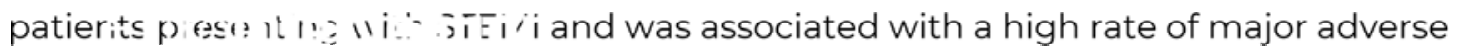
cardiovascular events and target vessel revascularisation at three years (29.9\% and $20.4 \%$, respectively) 14 .

In an attempt to find methods to improve outcome in these patients, a retrospective study in a large cohort of patients presenting with acute myocardial infarction reported that IABP support was used to treat persistent ischaemia in $2 \%$ of the cases. In these patients, one-year survival was $89 \% 11$.

The use of IABP in the presence of persistent ischaemia has not been extensively investigated, but its concept is plausible. The use of IABP is suggested to be effective by, for instance, increasing diastolic aortic pressure, aimed at improving coronary blood flow and myocardial oxygenation. However, with (partially) intact coronary autoregulation, corresponding with the absence of (persistent) ischaemia, it is illusionary to expect that a higher aortic pressure will result in increased coronary blood flow 16 . On the contrary, in patients presenting with STEMI, adequate epicardial reperfusion, but complicated by persistent ischaemia (or no-reflow) as reflected by insufficient ST-R, coronary autoregulation is completely exhausted.

Persistent ischaemia or no-reflow is caused by a variety of factors, including intramyocardial oedema, spasm, and distal embolisation 17. In this situation, myocardial blood flow is proportional to perfusion pressure, which is augmented by the diastolic inflation of the IABP, thereby increasing coronary blood flow and increasing oxygen utilisation by the myocardium. This, in turn, may limit infarct size and improve outcome. This concept, and the increase in myocardial oxygen supply in the presence of exhausted autoregulation, has recently been investigated by simultaneous coronary pressure and flow measurements in humans 18 .

Over $45 \%$ of the CRISP-AMI study population had ST-segment deviation of $<15 \mathrm{~mm}$, representing a cohort of relatively small or moderate infarctions with good prognosis anyway?. In fact, in such patients, only a small effect of IABP might be expected, thereby (significantly) decreasing the power of that study.

In the patients with large STEMI, $24 \%$ of the patients $(n=36)$ had signs of persistent ischaemia, which is the subgroup in whom benefit can be expected. This is also supported by the numerical survival estimates in Table 3, corroborating the hypothesis that IABP should be reserved for patients with large myocardial infarction and persistent ischaemia, and implies that the outcome of the original CRISP-AMI trial was confounded by the inclusion of a large group of patients with small myocardial infarction.

\section{LIMITATIONS AND UNRESOLVED ISSUES}

First of all, this study was a non-powered, non-pre-specified sub-analysis of the original CRISPAMI trial, implying that these results should be perceived only as hypothesis-generating and viewed with caution. However, as stated, there are few data on how to manage patients with continued evidence of poor reperfusion and ischaemia post primary PCI for STEMI.

Second, a small number of patients did not have both baseline ECGs and ECGs post PCI. These ECGs were missing or ST-R was not interpretable due to conduction abnormalities or arrhythmias. It is unlikely that these excluded patients would have altered the outcome of this study. In only one case, ECG post PCI was not available because the patient died in the catheterisation laboratory (randomised to the control group).
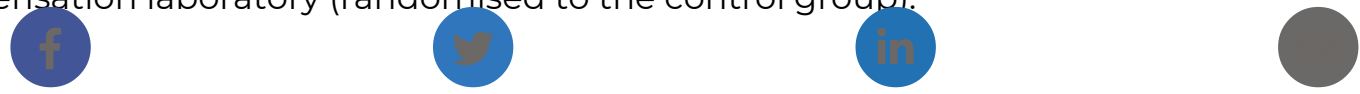
Third, there was a very high crossover rate from the control group to the IABP group in this sub-a ralysis (? : patients died prior to hospital discharge, while the other two patients reached the six-month follow-up without further events. It is unclear in what way the crossover influenced the results, since the role of IABP support in the treatment of cardiogenic shock is currently under debate. The IABP-SHOCK II trial showed no reduction in short-term and one-year mortality of IABP support in patients with AMI complicated by cardiogenic shock when compared to standard treatment without IABP support19,20. Both in the IABP-SHOCK II trial and in this substudy, asymmetrical crossover to the IABP group was present. One may wonder if an intention-totreat analysis is suitable in these open, non-blinded studies with a high event rate and considerable asymmetrical crossover. Apparently, the treating physician felt the need to violate protocol and to cross over from control to therapy group, thereby possibly diluting or masking a positive effect of the study device when assessed by intention-to-treat analysis, perprotocol analysis, or as-treated analysis. In the event that this asymmetrical crossover is of influence, it will create a negative bias for IABP, thereby corroborating the results shown in this substudy.

Fourth, comparing MRI results showed no difference in infarct size. However, four patients in the control group died before undergoing MRI. These patients probably suffered from the most severe myocardial infarctions and, by excluding them from the MRI assessment, the average value of infarct size in the control group is underestimated.

Finally, since IABP therapy was randomised and initiated before PCI, IABP support in itself might be responsible for better ST-R at the ECG post PCI. Therefore, the population suffering from persistent ischaemia, had they not received IABP, might in fact have been larger than recorded in this study with 15 patients in the IABP group versus 21 patients in the control group. Also, this might have diluted the beneficial effect of IABP in this study, which is present regardless, and thereby underscores the main finding of this study, i.e., decreased mortality by IABP therapy.

\section{Conclusion}

In this substudy in large ST-elevation myocardial infarction complicated by persistent ischaemia after successful primary $\mathrm{PCl}$, the use of IABP decreased mortality at six months. These results mandate further prospective randomised trials as to the beneficial effect of intraaortic balloon pump counterpulsation in this high-risk population.

\section{Impact on daily practice}

In patients admitted with large myocardial infarction, undergoing successful primary percutaneous coronary intervention, but complicated by persistent ischaemia as reflected by insufficient resolution of ST deviation, use of intra-aortic balloon pump counterpulsation significantly reduced mortality in this substudy. Therefore, despite guidelines not to use IABP routinely in acute myocardial infarction, selective use of this support device in these specific patients may be life-saving and should be considered and be readily available in the interventional catheterisation laboratory.
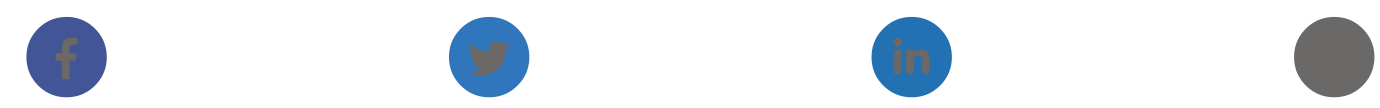


\section{Funding}

This work was supported by the Dutch Technology Foundation STW (Stichting voor de Technische Wetenschappen) under project number 11052. The original CRISP-AMI trial was funded by Maquet (formerly Datascope). The sponsor had no role in the design and conduct of the study, in the collection, analysis and interpretation of the data, or in the preparation, review or approval of the manuscript.

\section{Conflict of interest statement}

L. van Nunen has received reimbursement for travel expenses and speaker's fees from Maquet. M. Patel declares that his institution has received grant funding and reimbursement of travel expenses from Maquet. N. Pijls has received an unrestricted institutional research grant, reimbursements for travel expenses and speaker's fees from Maquet. The other authors have no conflicts of interest to declare.

$$
\text { coronary autoregulation intra-aortic balloon pump myocardial infarction }
$$

percutaneous coronary intervention persistent ischaemia

\section{References}

1. Kantrowitz A, Tjonneland S, Freed PS, Phillips SJ, Butner AN, Sherman JL Jr. Initial clinical experience with intraaortic balloon pumping in cardiogenic shock. JAMA. 1968;203:113-8.

2. Kern MJ, Aguirre FV, Tatineni S, Penick D, Serota H, Donohue T, Walter K. Enhanced coronary blood flow velocity during intraaortic balloon counterpulsation in critically ill patients. J Am Coll Cardiol. 1993;21:359-68.

3. Prondzinsky R, Lemm H, Swyter M, Wegener N, Unverzagt S, Carter JM, Russ M, Schlitt A, Buerke U, Cristoph A, Schmidt H, Winkler M, Thiery J, Werdan K, Buerke M. Intra-aortic balloon counterpulsation in patients with acute myocardial infarction complicated by cardiogenic shock: the prospective, randomized IABP SHOCK Trial for attenuation of multiorgan dysfunction syndrome. Crit Care Med. 2010;38:152-60.

4. Patel MR, Smalling RW, Thiele H, Barnhart HX, Zhou Y, Chandra P, Chew D, Cohen M, French J, Perera D, Ohman EM. Intra-aortic balloon counterpulsation and infarct size in patients with acute anterior myocardial infarction without shock: the CRISP AMI randomized trial. JAMA. 2011;306:1329-37.

5. Hallén J, Sejersten M, Johanson P, Atar D, Clemmensen PM. Influence of ST-segment recovery on infarct size and ejection fraction in patients with ST-segment elevation myocardial infarction receiving primary percutaneous coronary intervention. Am J Cardiol. 2010;105:1223-8.

6. Schröder R, Dissmann R, Brüggemann T, Wegscheider K, Linderer T, Tebbe U, Neuhaus KL. Extent of early ST segment elevation resolution: a simple but strong predictor of outcome in patients with acute myocardial infarction. J Am Coll Cardiol. 1994;24:384-91.

7. Schröder K, Wegscheider K, Zeymer U, Tebbe U, Schröder R. Extent of ST-segment deviation in a single electrocardiogram lead $90 \mathrm{~min}$ after thrombolysis as a predictor of medium-term mortality in acute myocardial infarction. Lancet. 2001;358:1479-86.

8. Mehta RH, Harjai KJ, Cox D, Stone GW, Brodie B, Boura J, O'Neill W, Grines CL; Primary Angioplasty in Myocardial Infarction (PAMI) Investigators. Clinical and angiographic correlates and outcomes of suboptimal coronary flow inpatients with acute myocardial infarction undergoing primary percutaneous coronary intervention. J Am Coll Cardiol. 2003;42:1739-46.
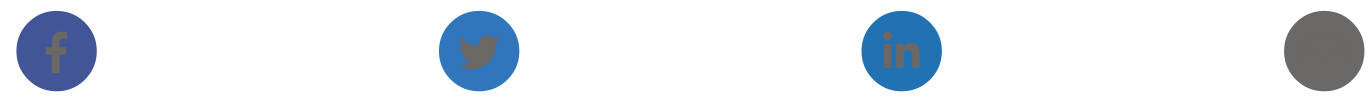
9. Rezkalla SH, Dharmashankar KC, Abdalrahman IB, Kloner RA. No-reflow phenomenon following

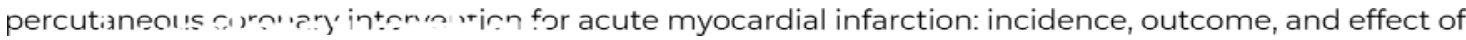
pharmacoiogic therapy. j Interv Lardıol. 2010;23:429-36.

10. Pierrakos CN, Bonios MJ, Drakos SG, Charitos El, Tsolakis EJ, Ntalianis A, Nanas SN, Charitos CE, Nanas JN, Terrovitis JV. Mechanical assistance by intra-aortic balloon pump counterpulsation during reperfusion increases coronary blood flow and mitigates the no-reflow phenomenon: an experimental study. Artif Organs. 2011;35:86774.

11. van Nunen LX, van 't Veer M, Schampaert S, Steerneman BJ, Rutten MC, van de Vosse FN, Pijls NH. Intra-aortic balloon counterpulsation in acute myocardial infarction: old and emerging indications. Neth Heart $\mathrm{J}$. 2013;21:554-60.

12. Patel MR, Thiele H, Smalling RW, Chandra P, Zhou Y, Cohen M, Perera D, Ohman EM. A multicenter, randomized, controlled study of mechanical left ventricular unloading with counterpulsation to reduce infarct size prepercutaneous coronary intervention for acute myocardial infarction: rationale and design of the Counterpulsation Reduces Infarct Size Acute Myocardial Infarction trial. Am Heart J. 2011;162:47-55.

13. [No authors listed]. An international randomized trial comparing four thrombolytic strategies for acute myocardial infarction. The GUSTO investigators. N Engl J Med. 1993;329:673-82.

14. Farkouh ME, Reiffel J, Dressler O, Nikolsky E, Parise H, Cristea E, Baran DA, Dizon J, Merab JP, Lansky AJ, Mehran R, Stone GW. Relationship between ST-segment recovery and clinical outcomes after primary percutaneous coronary intervention: the HORIZONS-AMI ECG substudy report. Circ Cardiovasc Interv. 2013;6:216-23.

15. Buller CE, Fu Y, Mahaffey KW, Todaro TG, Adams P, Westerhout CM, White HD, van 't Hof AW, van de Werf FJ, Wagner GS, Granger CB, Armstrong PW. ST-segment recovery and outcome after primary percutaneous coronary intervention for ST-elevation myocardial infarction: insights from the Assessment of Pexelizumab in Acute Myocardial Infarction (APEX-AMI) trial. Circulation. 2008;118:1335-46.

16. Pijls NH, De Bruyne B. Coronary pressure measurement and fractional flow reserve. Heart. 1998;80:539-42.

17. Rezkalla SH, Kloner RA. No-reflow phenomenon. Circulation. 2002;105:656-62.

18. De Silva K, Lumley M, Kailey B, Alastruey J, Guilcher A, Asrress KN, Plein S, Marber M, Redwood S, Perera D. Coronary and microvascular physiology during intra-aortic balloon counterpulsation. JACC Cardiovasc Interv. 2014;7:631-40.

19. Thiele H, Zeymer U, Neumann FJ, Ferenc M, Olbrich HG, Hausleiter J, Richardt G, Hennersdorf M, Empen K, Fuernau G, Desch S, Eitel I, Hambrecht R, Fuhrmann J, Böhm M, Ebelt H, Schneider S, Schuler G, Werdan K; IABP-SHOCK II Trial Investigators. Intraaortic balloon support for myocardial infarction with cardiogenic shock. N Engl J Med. 2012;367:1287-96.

20. Thiele H, Zeymer U, Neumann FJ, Ferenc M, Olbrich HG, Hausleiter J, de Waha A, Richardt G, Hennersdorf M, Empen K, Fuernau G, Desch S, Eitel I, Hambrecht R, Lauer B, Böhm M, Ebelt H, Schneider S, Werdan K, Schuler G; Intraaortic Balloon Pump in cardiogenic shock II (IABP-SHOCK II) trial investigators. Intra-aortic balloon counterpulsation in acute myocardial infarction complicated by cardiogenic shock (IABP-SHOCK II): final 12 month results of a randomised, open-label trial. Lancet. 2013;382:1638-45. 